\title{
La dictadura militar en el campo chaqueño. Una aproximación a sus características, temporalidades y magnitudes ${ }^{1}$
}

\section{The military dictatorship in the Chaco countryside. An approximation to its characteristics, temporalities and magnitudes}

Claudia Calvo ${ }^{2}$

\section{Resumen}

Hacia fines de los años sesenta el campesinado del noreste del país, nucleado alrededor de los complejos agroindustriales, asistió a un proceso de movilización política. En noviembre de 1970 en Chaco se crearon las Ligas Agrarias, tras la confluencia de la Unión de Jóvenes cooperativistas y el Movimiento Rural de Acción Católica. Impulsaron la distribución y titulación de la tierra, la regulación de la comercialización y la producción por parte del Estado. Enfrentaron a los monopolios de la comercialización y al poder terrateniente. Partícipes del proceso de radicalización popular, las Ligas sufrieron la persecución política desde inicios de 1975. Acusados de subversivos, sus principales dirigentes fueron detenidos y las bases acosadas por fuerzas parapoliciales. Con el golpe de Estado de 1976 fueron desmanteladas. Este artículo analiza las características que asumió la represión en el campo a partir del golpe de Estado de 1976, atendiendo a las continuidades y rupturas que supuso el

\begin{abstract}
Towards the end of the 1960s, the peasantry in the northeast of the country, nucleated around the agro-industrial complexes, witnessed a process of political mobilization. In November 1970 in Chaco the Agrarian Leagues were created, after the confluence of the Union of Young Cooperatives and the Rural Movement of Catholic Action. They promoted the distribution and titling of land, the regulation of commercialization and production by the State. They faced the monopolies of commercialization and landlord power. Participants in the process of popular radicalization, the Leagues suffered political persecution since the beginning of 1975. Accused of being subversives, their main leaders were arrested and the bases harassed by para-police forces. With the 1976 coup they were dismantled. This article analyzes the characteristics that repression assumed in the countryside as of the 1976 coup d'état, taking into account the continuities and ruptures that the institu-
\end{abstract}

1 Trabajo recibido el 20/05/2020. Aceptado el 18/07/2020.

${ }^{2}$ Universidad de Buenos Aires. Contacto: claudiaecalvo@gmail.com 
quiebre institucional en la dinámica y características de la violencia estatal y para estatal sobre las Ligas ya desde comienzos de la década. El trabajo apunta a reflexionar sobre la el modo en que se inscribió regionalmente el terrorismo de Estado antes y después del golpe.

Palabras clave: ligas agrarias; terrorismo de Estado; Chaco. tional breakdown in the dynamics and characteristics of state and para-state violence on the Leagues since the beginning of the decade. The work aims to reflect on the way in which State terrorism was registered regionally before and after the coup.

Keywords: agrarian leagues; state terrorism; Chaco.

\section{Introducción}

Hacia fines de los años sesenta el campesinado en el noreste argentino, nucleado alrededor de los complejos agroindustriales, asistió a un proceso de movilización política. En noviembre de 1970 en Chaco se crearon las Ligas Agrarias, tras la confluencia de la Unión de Jóvenes cooperativistas y el Movimiento Rural de Acción Católica (MR). Desde mediados de los años sesenta la provincia padecía una profunda crisis por la baja del precio del algodón, ${ }^{3}$ principal actividad productiva alrededor de la cual se articulaban subordinadamente las explotaciones campesinas como proveedoras de la materia prima a través de las cooperativas. $^{4}$

Las Ligas impulsaron la distribución y titulación de la tierra, la regulación de la comercialización y la producción por parte del Estado y enfrentaron a los monopolios de la comercialización y al poder terrateniente. ${ }^{5}$ Partícipes del proceso de radicalización popular, sufrieron la per-

\footnotetext{
${ }^{3}$ En la campaña 1966/67 la siembra de algodón cayó de 400.000 a 195.000 hectáreas y la producción de fibra de 91500 a 38000 toneladas (Lovey, 2018, p. 12). El deterioro progresivo de sus precios respondía a la política de desaliento del cultivo a favor de la diversificación hacía graníferas y el desarrollo de la ganadería complementaria, que permitía liberar las mejores tierras de la pampa húmeda para el engorde de ganadería vacuna de exportación (Roze, 1992). Esta crisis alcanzó su pico a mediados de 1970, coincidiendo con el alza progresiva de la movilización de amplios sectores sociales en el país.

${ }^{4}$ Surgida en 1943, la Unión de Cooperativas Algodoneras Limitadas (UCAL) nucleaba en 1960 más de 15.000 socios en 31 cooperativas, representando el $57 \%$ de los agricultores y el 69\% de los específicamente algodoneros (Carlino, 2007).

${ }^{5}$ Hasta su desmantelamiento con el golpe de 1976, una amplia cantidad de agentes con desigual poder de negociación convivió en el circuito algodonero pese a que las decisiones económicas sobre las condiciones de producción y reproducción de los medios de vida
} 
secución política desde inicios de 1975, cuando, acusados de subversivos, sus principales dirigentes fueron detenidos y las bases acosadas por fuerzas parapoliciales. La asociación de las Ligas al extremismo y la persecución padecida desde los primeros años setenta allanó el camino para la pronta desmovilización de las bases liguistas. Tras el golpe de Estado el movimiento fue desmantelado.

El 27 de septiembre de 1977 Ramón Chávez andaba en bicicleta por los caminos rurales de Santa Teresina, provincia de Corrientes, cuando fue detenido ilegalmente por las fuerzas conjuntas de la policía local y el ejército. Con los ojos vendados y las manos esposadas, padeció el interrogatorio, la extorción y fue torturado física y psicológicamente durante 45 días, mientras era trasladado de un lugar a otro, previo a ingresar en la Brigada de Investigaciones, el principal centro clandestino de detención del noreste, ubicado en el centro de la capital chaqueña frente a la gobernación. ${ }^{\top}$ No era la primera vez que lo detenían por motivos políticos, pero sí la última, puesto que permaneció cautivo en diversas cárceles del país hasta su liberación a fines de 1983. Sus últimos años de encierro los vivió en la cárcel de máxima seguridad de Rawson, en la provincia de Chubut.

Nacido en la localidad de Empedrado, Corrientes, en 1946, en el seno de una familia de peones rurales, Chávez migró a Chaco para la cosecha del algodón, donde se asentó definitivamente. A los 20 años se convirtió en uno de los más importantes activistas campesinos del norte de la provincia. Participó en el $\mathrm{MR}^{7}$ y en las Ligas Agrarias, promovien-

estaban en manos de 3 empresas comercializadoras (Clayton, Dreyfus y Bunge y Born) que fijaban los precios, lo cual, en contextos de crisis, reforzaba la asimetría entre la oferta atomizada y la demanda concentrada.

${ }^{6}$ En 2005 fue sancionada la Ley No 1412 A (ex No 5582) que creó la Comisión Provincial de la Memoria. Desde entonces allí funciona la Casa de la Memoria, el Mueso de la Memoria, el Registro Único de la Verdad, entre otros organismos de preservación de la memoria histórica.

${ }^{7}$ Hacia fines de los '50 una nueva conciencia social y política se gestó al interior de la iglesia, un «dislocamiento social» respecto de su función en la sociedad así como una nueva conciencia de sí misma y de su misión, vinculada a la opción preferencial por los pobres y a una pastoral popular liberadora (Moyano, 1992, p. 369). Progresivamente la Iglesia comenzó a incidir en el surgimiento de sindicatos rurales cristianos y de diversos movimientos rurales en el Cono Sur del continente, especialmente en Chile, Argentina, Paraguay y Brasil. En el ámbito rural de Argentina, este «dislocamiento» generó importantes consecuencias a partir de la formación de líderes campesinos, que, poco a poco, fueron potenciando su compromiso con la situación de explotación de los sectores subalternos del campo y politizando sus 
do la organización y la formación de las familias campesinas, hasta mediados de 1975 cuando la organización fue descabezada. Chávez fue el último de los delegados zonales en ser detenido durante la dictadura, en septiembre de 1977.Su esposa Mirta, también activa partícipe de las Ligas, cargó a su pequeño hijo y siguió el recorrido de su cautiverio, por diversas ciudades del país. También estuvo desaparecida un mes a fines del 77.

La historia de Ramón y Mirta retrata la represión política en las zonas rurales de Argentina, aspecto del campo de estudios de la memoria social y la historia reciente que ha sido escasamente estudiado. Este tópico también ha permanecido silenciado en la mayor parte de las investigaciones sobre las Ligas Agrarias. ${ }^{8}$ En Argentina, las investigaciones sobre las representaciones obreras y campesinas de la violencia política y el terrorismo de Estado surgieron tardíamente, pese a la importancia cuantitativa y cualitativa de la represión a estos actores. Aun tras su aparición, su estudio quedó circunscripto casi exclusivamente a las grandes ciudades y sus periferias (James, 2004; Maceira, 2005; Maneiro, 2005; Lorenz, 2007). Entrados los años dos mil comenzaron a surgir

demandas, especialmente a través del trabajo del MR. Este movimiento surgió en 1958 como una iniciativa de un sector del obispado y reconocido como una rama de la Acción Católica Argentina puesto que la Iglesia requería al ámbito rural como base social propia en un contexto de recomposición del espacio social cristiano en el terreno político, en el marco del proceso revolucionario cubano y la alianza para el progreso.

${ }^{8}$ A modo de excepción véase la tesis doctoral de Mercedes Moyano, recientemente publicada (2020) y Calvo (2015).Las Ligas Agrarias fueron estudiadas desde diversos ángulos: como un movimiento homogéneo y autónomo con potencialidad revolucionaria (Ferrara, 1973), o destacando la heterogeneidad de su composición social y sus diferencias organizativas y políticas en cada provincia (Archetti, 1988; Roze, 1992; Galafassi, 2005; Ferragut, 2015). Otras investigaciones examinaron sus antecedentes en los sectores rurales subalternos ya sea organizados por la Iglesia Católica (Lasa, 1985; Moyano, 1992; 2009; Vázquez, 2017) y/o influidos por la experiencia de las Ligas Paraguayas producto de los procesos migratorios (Vázquez, 2015) o su papel como actor en el conflicto social y político en los años setenta (Roze, 2007; 2008). Desde una perspectiva histórica, fue estudiada la tradición cooperativista de las Ligas como herramienta de lucha y resistencia (Villalva, 2004). Desde la antropología, fueron analizadas en función de su composición de clase y sus demandas (Bartolomé, 1977; 1982). Otros estudios más recientes, las examinaron desde la perspectiva de los «nuevos movimientos sociales» y la «dinámica de la acción colectiva» (Bidaseca, 2007; Masín, 2009; Galafassi, 2007; Percíncula, Buzzela, Soma, 2008; Moyano, 2011; Calvo y Percíncula, 2012). Otros análisis se enfocaron en la revisión histórica de las investigaciones que tomaron a las Ligas como objeto de estudio (Roze, 2010). Finalmente, recientemente quien fue su máximo dirigente, Osvaldo Lovey, publicó un libro autobiográfico sobre la historia de las Ligas Agrarias de Chaco (Lovey, 2018) 
estudios sobre las memorias de las comunidades rurales y sus tensiones con las memorias nacionales, tanto en el Cono Sur (Reyes Novaes, 2001; Jelin y Del Pino, 2003; Theidon, 2003; Rodríguez Maeso, 2011), como también, aunque en menor medida, en Argentina (Da Silva Catela, 2003, 2006 y 2007; Figurelli, 2008; Da Silva Catela y Esposito, 2013; Calvo, 2015). ${ }^{9}$

Precisamente, este artículo analiza las características que asumió la represión en el campo a partir del golpe de Estado de 1976, atendiendo a las continuidades y rupturas que supuso el quiebre institucional en la dinámica de la violencia estatal y paraestatal que venía ejerciéndose sobre las Ligas desde comienzos de la década. ${ }^{10}$ El trabajo propone abonar a la construcción de conocimiento sobre el modo en que se inscribió regionalmente el terrorismo de Estado antes y después del golpe. Para ello examino testimonios orales de ex miembros de las Ligas, del Movimiento Rural y del peronismo local; y reviso la prensa provincial, el órgano de difusión liguista y otros documentos que circularon durante el periodo, disponibles en los archivos públicos especializados. ${ }^{11}$

\section{Preludios del golpe de Estado en las zonas rurales}

El golpe de 1976 emergió como respuesta a un proceso histórico largo en el que se fue construyendo una realidad sobre la «violencia» y sus responsables, un clima de consentimiento, y de aceptación tácita (Franco, 2012, Romero, 2007, Vezzetti, 2002). De manera progresiva, el discurso dominante comenzó a ser el de la ilegitimidad de «la violencia» con el cual fueron justificados discursos y prácticas represivas que se acumularon hasta 1976. Las Ligas Agrarias chaqueñas no permanecieron ajenas a este proceso. El 24 de marzo de 1976 la dirigencia estaba presa, desaparecida o clandestinizada en el monte. Su asociación al ex-

\footnotetext{
${ }^{9}$ Con la excepción del texto canónico de Silvia Ribera Cucicanqui, publicado en 1984 «Oprimidos pero no vencidos. Luchas del campesinado Aymara y Quechua 1900-1980» y una década más tarde, el trabajo de Alejandro Isla y Julie Taylor (1995), ambos de temprana aparición.

${ }^{10}$ En efecto, ya desde 1972 las Ligas comenzaron a ser perseguidas, cuando la Iglesia a través de su obispo abandonó el acompañamiento del campesinado organizado, y en consecuencia progresivamente fueron perdiendo legitimidad entre la población rural. Al respecto, véase Calvo (2020).

${ }^{11}$ En particular, utilicé el material del archivo Plancot, disponible en la Universidad Nacional General Sarmiento, donado por el cura Carlos Plancot en 2013.
} 
tremismo y la temprana persecución facilitó la pronta desmovilización de las bases campesinas. Este proceso adquirió contornos particulares.

Las primeras detenciones de campesinos ocurrieron en los primeros meses de 1975, sobre todo, tras el paro agrario de enero y febrero ${ }^{12}$ cuando fue paralizada la producción y comercialización del algodón y el girasol, luego de un extenso plan de lucha con un alto nivel de acatamiento (Roze, 1992, p. 278). Pese que la medida logró revertir los precios del girasol, los diarios locales solo informaron enfáticamente la no entrega de granos y el incendio de los transportes que no acataban la medida de fuerza. ${ }^{13}$ Las detenciones en el campo continuaron en marzo $\mathrm{y}$ abril ${ }^{14}$ hasta que a mediados de ese messe produjo la mayor operación de las fuerzas conjuntas en el interior provincial con la detención de los máximos cuadros liguistas. ${ }^{15}$ El 25 de abril el diario Norte informaba que a partir del 17 la policía de Chaco había orientado la represión hacia las áreas rurales y advertía sobre la participación activa de integrantes de las Ligas Agrarias en hechos terroristas como el atentado contra oficinas de Bunge y Born en Sáenz Peña en 1974, la quema del camión girasolero en Tres Isletas y el atentado y desarme del cabo de policía Lezama. ${ }^{16}$ Precisaba que

la jefatura de policía de la provincia (...) cumple en informar a la población que 1) desde el día 17 del corriente mes y año en la ciudad de Presidente Roque Sáenz Peña se efectuaron detenciones y allanamientos, con intervención de la justicia federal, lo que permitió comprobar que personas pertenecientes a las Ligas Agrarias Chaqueñas realizaban encubiertamente actividades netamente subversivas y militaban en organizaciones proscriptas ${ }^{17}$

Osvaldo Lovey, ${ }^{18}$ su compañera Adelina de León ${ }^{19}$ y el asesor legal

${ }^{12}$ La Opinión, 02/03/1975.

${ }_{13}^{13}$ Norte, 24/01/1975.

${ }^{14}$ Las Ligas presentaron una denuncia al secretario del Ministerio del Interior de la Nación, Ing. Beltrán por la detención de agricultores liguistas, tras el paro agrario de febrero. Evita Montonera, (5), junio de 1975.

${ }^{15}$ El Territorio, 20 al 25/04/1975.

${ }^{16}$ Norte, $25 / 04 / 1975$.

${ }^{17}$ Norte, 25/04/1975.

${ }^{18}$ Oriundo de Machagay, de familia de medianos productores cooperativistas, Lovey fue el Secretario General de las Ligas Agrarias Chaqueñas y Coordinador Nacional de las Ligas y Movimientos de Base.

${ }^{19}$ Nacida en Buenos Aires a fines de los años 40. En 1969 se recibió de maestra e ingresó a 
de la organización, Luís Rodríguez, ${ }^{20}$ fueron detenidos en Sáenz Peña y permanecieron varios meses desaparecidos. Otros dirigentes que lograron escapar fueron declarados «prófugos de la subversión». ${ }^{21}$ También una veintena de militantes de la Juventud Peronista, recientemente volcados al trabajo con el campesinado algodonero, fue detenida en Villa Ángela. ${ }^{22}$

Luego de permanecer varios días en la comisaría del pueblo, los detenidos fueron trasladados a la Brigada de Investigaciones, dependiente de la VII Brigada de Infantería con asiento en Corrientes y comandado por el general Nicolaides. ${ }^{23}$ Padecieron la tortura y el interrogatorio, y verificaron cómo llevaban a otros cautivos a recorrer la ciudad para la delación de militantes. Es decir que, bajo el gobierno democrático de Bittel ya existía un modus operandi del terrorismo de estado basado en la utilización del interrogatorio bajo apremios físico-psicológicos, ${ }^{24} \mathrm{del}$ que participaban el Departamento de Informaciones Especiales y la Delegación de la Policía Provincial, el Destacamento de Inteligencia $124 \mathrm{del}$ Ejército, Gendarmería Nacional, Subprefectura Naval, Servicio Penitenciario Nacional y Fuerza Aérea Argentina. La Brigada de Investigaciones alojaba a los detenidos que se encontraban a disposición del Área

la facultad de sociología. Conoció la realidad campesina de Chaco por los viajes que realizó a las colonias rurales junto a compañeros de facultad. Se integró en las Ligas y participó de la Comisión Central. Estuvo desaparecida entre agosto de 1976 y diciembre del mismo año, cautiva en la Brigada de Investigaciones de Resistencia.

${ }^{20}$ Oriundo de Santa Fe y proveniente de la militancia estudiantil peronista y del cristianismo, se radicó en el interior rural de Chaco en 1969 por pedido del Obispo de Sáenz Peña, Monseñor Ítalo Di Stefano, para colaborar con la organización del campesinado. Fue su asesor legal.

${ }^{21}$ Entre otros, Carlos Piccoli, Carlos Orianski, Remo Vénica y Armando Molina. El Territorio, 20 al 25/04/1975.

${ }^{22}$ Entrevista de la autora a Jorge Giles, Buenos Aires 20/09/2018.

${ }^{23}$ En la provincia de Chaco existieron al menos cuatro centros de detención clandestina: la Brigada de Investigaciones, la Alcaldía Policial, la cárcel Unidad 7 y el Regimiento de la Liguria, todos ubicados en la ciudad de Resistencia y zonas cercanas a esta. Además, las comisarías de los pueblos funcionaron como centros de detención ilegal de los pobladores rurales detenidos durante días o semanas. La mayor parte de los centros ya funcionaba previo al golpe del ' 76 .

${ }^{24}$ Recuérdese la simultaneidad de estos procedimientos en el noreste con las operaciones militares que se estaban desplegando en las mismas fechas en Tucumán, a instancias del Operativo Independencia, que autorizaba al Ejercito a intervenir en la «lucha antisubversiva» en la provincia. 
militar 233 hasta el final de la faz interrogativa para ser trasladados luego a la Alcaldía Policial o asesinados. ${ }^{25}$

Durante esos meses continuaron las operaciones militares en el interior: las fuerzas conjuntas recorrían las colonias, «levantaban» campesinos durante el día y la noche y los trasladaban en camiones de animales. Así, fueron detenidos decenas de pobladores campesinos y sus colaboradores. $^{26}$

A mitad del '75, en un contexto de doble crisis económica por la hiperinflación nacional y por los stocks acumulados de algodón, comenzó a generalizarse el clima de ilegalidad en torno a las Ligas, relegadas también del plano gremial. Las amenazas a sus cuadros generaron un vacío en la convocatoria y la desmovilización de las colonias. En los meses que siguieron la acción de las Ligas consistió meramente en la difusión de comunicados y solicitadas sobre la situación económica.

Los referentes liguistas fueron liberados en agosto tras una intensa presión popular de organizaciones externas con las que habían tejido lazos desde la época del MR. ${ }^{27}$ Sin el apoyo material (dinero, autos para recorrer los campos) y simbólico (legitimidad) de la Iglesia, se volcaron a la clandestinidad en el monte, un refugio donde podían sobrevivir. El monte era un territorio conocido para los liguistas e inaccesible para los agentes estatales y las fuerzas de seguridad. Frente a la persecución no había sitio más seguro para resguardar a los cuadros más activos de la organización; en definitiva, no había otro recurso de preservación de la propia vida. Poco a poco la decisión de «perderse» ${ }^{28}$ en el monte dejó de ser una experiencia excepcional, para volverse parte del repertorio de acciones de resistencia individual y colectiva. ${ }^{29}$

Una última acción pública de las Ligas tuvo lugar un mes más tarde en Castelli cuando unos 3000 productores se concentraron sin la presencia física de sus máximos dirigentes. Una cinta grabada con el

\footnotetext{
${ }^{25}$ Véase, Comisión Provincial por la Memoria de Chaco, disponible en www. comisiónporlamemoria.chago.gov.ar

${ }^{26}$ Entre ellos, los activistas Filomeno Chávez, Filemon Sánchez y a la esposa del dirigente Carlos Orianski. Y el francés Charles Plancot colaborador de las Ligas de la diócesis de Sáenz Peña, acusado de tenencia de armas de guerra y material subversivo. Evita Montonera, 5, Junio de 1975.

27 Clarin, 05/08/1975.

${ }^{28}$ Expresión utilizada por los testimonios para enunciar su experiencia de clandestinización.

${ }^{29}$ El insilio rural ha sido poco examinado en los estudios sobre la resistencia en tiempos de dictadura. Véase el libro canónico de Jorge Miceli Montemadre (2006) y el film de Juan Baldana Los del Suelo (2015).
} 
mensaje del dirigente Carlos Orianski, ${ }^{30}$ escondido en el monte, fue transmitida por altoparlante. ${ }^{31}$ En aquella jornada se pidió el cese de persecución a los liguistas y se responsabilizó al gobierno nacional por la crisis económica y su falta de control en las agroindustrias (Roze, 1992, p. 90). Lovey recuerda que

la última movilización que hicimos fue cuando me largan luego de 111 días. Después de eso ya no hicimos más. A partir de ahí la represión ya se hizo ostensible, imucho antes del golpe, eh! Es más, tampoco salieron en libertad ni un preso político más. Se sabía que estaba tomada la decisión del golpe de estado... tal es así que después de esa concentración, a los pocos días, me fueron a buscar devuelta, si yo no eludo me hubieran metido en cana y me hubieran chupado como 8 años ${ }^{32}$

Para septiembre todos los dirigentes liguistas se encontraban clandestinizados. Tanto el VI Cabildo Abierto como el Congreso planificados para octubre debieronser suspendido por la voladura de un local de la organización en Quitilipi. Esta vez las amenazas no pudieron ser repudiadas con la presencia masiva de agricultores en las rutas (Roze, 2007, pp. 85-86). A partir de entonces ya no se realizaron acciones bajo el nombre del movimiento.

En resumen, en abril del 75 las Ligas fueron descabezadas. Mientras continuaban las detenciones ilegales, las «visitas» en las casas de las familias y los rodeos por los campos con helicópteros de las fuerzas de seguridad, sus dirigentes fueron asumiendo la clandestinidad. Durante todo ese año fue allanado el camino para la ocupación permanente de las zonas algodoneras de la provincia. El rol de la policía local, ${ }^{33}$ los años

\footnotetext{
${ }^{30}$ Dirigente liguista que provenía de la Unión de Centros Cooperativistas, llegó a ser nombrado vocal del Instituto de Colonización en 1973. Fue el promotor del proyecto de fundación de una Universidad agro-técnica en Sáenz Peña para el campesinado chaqueño que nunca pudo llevarse a cabo. Actualmente se encuentra desaparecido.

${ }^{31}$ Crisol, 16/08/1975. El diario señala que Orianski se encontraba «prófugo» y con pedido de captura.

${ }^{32}$ Entrevista a Quique Lovey, Tres Isletas (Chaco), marzo de 2011.

${ }^{33}$ A diferencia de lo ocurrido en otras provincias, en Chaco no ha habido acceso a la documentación desclasificada de la policía y sus organismos de inteligencia. Cuando la Comisión Provincial de la Memoria de Chaco solicitó documentación sobre la actuación policial durante el terrorismo de Estado, la institución policial adujo que, tras un incendio en la sede de la policía, se «había perdido» el material. Entrevista a Juan Carlos Fernández, director del Registro Único de la Verdad, CPM (Chaco) 30/04/2019 y entrevista a Diego
} 
previos, fue central para la intromisión del ejército: conocedora de las familias agricultoras y del territorio, asumió tareas de inteligencia y garantizó el alcance de la acción represiva, llegando a todos los parajes rurales. ${ }^{34}$

\section{La intervención militar y el «insilio» rural}

Tras el golpe de Estado se implementaron «Operativos Toba» en toda la región. En octubre del '76 el gobierno chaqueño designó el interior de la provincia como zona militar, desplazando efectivos del ejército y de gendarmería en todas las localidades y rutas principales. ${ }^{35}$ Los operativos se implementaron bajo el supuesto objetivo de «acercar las fuerzas armadas a la sociedad civil». Mediante la convocatoria a reuniones con la comunidad, con el pretexto de arreglar escuelas u otra institución estatal, las fuerzas militares extraían información sobre personas, lugares y/o documentos y viabilizaban la vigilancia y las detenciones. Estas acciones cívicas, que promovieron la delación y persecución al interior de la población rural, apuntaron a recuperar el apoyo de la población, el dominio de la zona y a aniquilar la subversión.

Vigay, fiscal ad hoc la Unidad de Asistencia para Causas por Violaciones de Derechos Humanos humanos durante el terrorismo de Estado de la fiscalía provincial, Resistencia (Chaco), abril de 2019,.

${ }_{34}$ Testimonio de Osvaldo Lovey vertido en la audiencia No 4 del juicio «Contraofensiva», Buenos Aires 14/05/2019.

${ }^{35}$ Informe sobre los Operativos Toba elaborado en 2014 por el Equipo de Trabajo en los Archivos del Ejército, Dirección de Derechos Humanos y Derecho Internacional Humanitario del Ministerio de Defensa de la Nación. Véase también el trabajo de Carlos Salamanca (2015) sobre las formas en las que el último gobierno militar se constituyó en los contextos locales y regionales de frontera; también Pamela Colombo (2018) examinó la política contra-insurreccional desarrollada por el último gobierno militar en Chaco tomando el caso de Fuerte Esperanza, en el Impenetrable chaqueño. Particularmente en el Chaco, se implementaron los Operativos Toba I y II. El documento titulado «Situación Subversiva Marco Jurisdiccional» menciona que mediante la ejecución del Toba I por parte del Comando Brigada de Infantería VII «se logra la reunión de importante información que posteriormente permiten detectar e individualizar a la mayoría de los integrantes de esta organización que se encontraban mimetizados dentro de la población y especialmente en la zona rural, donde encontraron campo propicio para la realización de sus fines, explotando en especial la situación económica por la que atraviesa el país; utilizando a las Ligas Agrarias como pantalla y aprovechando la ascendencia que tenían sobre los agricultores, sus principales dirigentes, caso Lovey, Oriansky, Piccolli, etc.» 
Previo a ello, durante la primera mitad de 1976, los delegados de las colonias mantuvieron el contacto con la dirigencia escondida en el monte, proveyendo alimentos, abrigo e información. De ese modo, sostuvieron mínimamente la estructura organizativa, oficiando de «mensajeros» entre el adentro (el monte) y el afuera, en un contexto en el que ya no había condiciones para convocar asambleas u otra acción colectiva en carácter de «Ligas agrarias». ${ }^{36}$ Se trataba de una porción del campesinado de base que había cumplido un rol fundamental en la organización de su colonia o lote, conformando lazos de confianza y solidaridad inéditas en la cultura política agraria. Y habían promovido la organización asamblearia en las colonias con métodos democráticos y participativos, constituyéndose en referencias públicas a nivel local para el conjunto de las familias campesinas. Este sector del activismo campesino fue el más castigado por la violencia estatal tras el golpe. La estrategia del gobierno militar fue su secuestro o asesinato, no solo con el fin de desmembrar definitivamente al movimiento sino también para disciplinar a la población rural. ${ }^{37}$ Centenares de campesinos fueron secuestrados durante todo el período: subidos a camiones de animales, trasladados de lote en lote durante todo el día y finalmente alojados en la Brigada de Investigaciones donde fueron torturados e interrogados. Tras su liberación, en muchos casos, debían volver caminando cientos de kilómetros hasta sus colonias en el interior provincial. ${ }^{38}$

En septiembre de 1977 el Comandante de la Séptima Brigada de Infantería, general Cristino Nicolaides se refirió a la « subversión rural» en Chaco al señalar que

${ }^{36}$ Entrevista a Jobino Fernández, Tres Isletas (Chaco), julio de 2013. En Fernández fue delegado del Lote 18 y mantuvo un estrecho contacto con el dirigente Carlos Piccoli mientras éste se encontraba refugiado en el monte. Sobre este tema también véase los testimonios de Osvaldo Lovey, vertido el 14 de mayo de 2019 en el marco del Juicio «contraofensiva», Tribunal Federal de San Martín, Buenos Aires y el de Remo Venica, vertido el 9 de junio de 2019 en el marco del Juicio «contraofensiva», en el Tribunal Federal de San Martín, Buenos Aires. También, entrevista realizada por la autora a Adelina de León, Buenos Aires 05/10/2018.

${ }^{37}$ A ello se refieren los testimonios cuando describen la constante exposición pública de cuerpos mutilados en las rutas o la vera de los ríos. Entrevista a Ramón Chávez, Tres Isletas (Chaco) 16/03/2011; entrevista a Quique Lovey, Tres Isletas (Chaco), 17/03/2011; Entrevista a Jorge Giles, Buenos Aires 20/09/2018; entrevista a Adelina de León, Buenos Aires 05/10/2018,; entrevista a Diego Vigay, Resistencia (Chaco) 11/04/2019.

${ }^{38}$ Entrevista a Dafne Zamudio, coordinadora del Programa de Asistencia Integral a Víctimas del Terrorismo de Estado, que acompaña a las víctimas y sus familiares que testimonian en los juicios por crímenes de lesa humanidad en Chaco, Resistencia (Chaco) 11/12/2019. 
el trabajo subversivo urbano se había trasladado a las zonas rurales, mediante el engaño y la utilización de reivindicaciones agrarias (...) la acción intensa desplegada permitió desmontar la organización actuante e inclusive detener a seis altos dirigentes del grupo Montoneros, infiltrados en la zona rural, numerosos dirigentes agrarios comprometidos en la acción subversiva también fueron detenidos ${ }^{39}$

Ese mismo mes fue detenido Ramón Chávez, el último de los delegados campesinos apresado por las fuerzas de seguridad. Luego del golpe había intentado esconderse en el monte, sin lograr tomar contacto con sus compañeros insiliados. Su familia padeció el hostigamiento cotidiano hasta quedar aislado del conjunto del activismo. Chávez relata que su detención tuvo un impacto simbólico muy alto en el conjunto de las familias campesinas de la localidad, incluso tras el retorno constitucional, en 1984, cuando quiso reinsertarse en la comunidad. ${ }^{40}$ Según expli$\mathrm{ca}$

La represión acá tuvo el objetivo principal era la intimidación de la población rural para que nunca se organice. Llegaban a las escuelas y allanaban para intimidar a todos los chicos. Mucho tiempo quedó ese miedo a las Ligas. Era más o menos un «cuco» viste para mucha gente. $^{41}$

A comienzos de octubre un comunicado de la VII Brigada de Infantería señalaba el riesgo que presentaba la zona rural de Chaco por haber sido «explotada» por la subversión, explicando que el ejército había detenido agricultores que «de una u otra manera» colaboraban con la subversión; aclaraba que los «primeros en huir» habían sido los «mal llamados dirigentes» y que se había encontrado dinero, armas, municiones y literatura marxista en las chacras allanadas. ${ }^{42}$ Durante todo ese mes, el ejército difundió comunicados a través de los diarios locales, donde justificaba la militarización del campo para la erradicación del extremismo. ${ }^{43}$ Así, persuadían a la comunidad rural sobre la importancia de denunciar a los liguistas por ser»elementos de un supuesto comunismo

\footnotetext{
${ }^{39}$ La Opinión, 25/09/1977.

${ }^{40}$ Entrevista realizada a Ramón Chávez, Tres Isletas (Chaco) marzo de 2011.

${ }^{41}$ Entrevista realizada a Ramón Chávez, Tres Isletas (Chaco) marzo de 2011.

${ }^{42}$ Norte, El Territorio y Crisol, octubre de 1976. Véase también Roze (1992, p. 90)

${ }^{43}$ Véase, en particular El Territorio y Norte.
} 
internacional». ${ }^{44}$ En la edición del 23 de octubre, El Territorio señalaba que los operativos llevaban tranquilidad a la población al desbaratar y desarticular la estructura de las organizaciones subversivas de la zona y denunciaba a los dirigentes campesinos «prófugos» acusándolos de partícipes de la subversión que encubren su actividad real autotitulándose reorganizadores de las Ligas Agrarias, los centros Juveniles o actividades rurales afines. ${ }^{45}$ Las estaciones de trenes, los comercios y las oficinas públicas fueron empapelados con afiches con las caras de los dirigentes campesinos, buscados por «subversivos», pidiendo su captura. Esta estrategia tuvo un altísimo impacto en la naturalización de la persecución: según los testimonios reprodujo el descredito y la delación entre la población campesina. ${ }^{46}$ La difusión del ideario subversivo influyó a tal punto en las familias rurales que algunas debieron migrar a otras provincias. Luis, primo de Carlos Piccoli, ${ }^{47}$ explica que a su tío, no lo dejaban salir de la chacra para que no viese los afiches con la foto de su hijo con la insignia «buscado». Hasta que «se escapó un día y vio los carteles, cuando volvió se suicidó».48Remo Venica, histórico dirigente campesino que trabajó como coordinador regional del MR, describe que los folletos con pedido de captura de los liguistas eran distribuidos por avionetas, sus nombres repetidos por la radio, con las más delirantes difamaciones como

\footnotetext{
${ }_{44}^{4}$ Testimonio de Quique Lovey vertido el 12/04/2019, en el Tribunal Oral No 1 de Resistencia en el marco de juicio «Ligas Agrarias l».

${ }^{45}$ El Territorio, 23/10/1976.

46 Entrevista realizada a Jorge Giles, Buenos Aires 20/09/2018; testimonio de Quique Lovey vertido el 12/04/2019, en el Tribunal Oral N ${ }^{\circ} 1$ de Resistencia en el marco de juicio «Ligas Agrarias I»; entrevista realizada a Mario Piccoli, Sáenz Peña 12/12/2019; testimonio vertido por Luís Piccoli, el 12/05/en el Juicio Contraofensiva, Tribunal Federal de San Martín, Buenos Aires.

${ }^{47}$ Fue uno de los más importantes dirigentes de las Ligas chaqueñas. Nacido en el seno de una familia de pequeños productores de identidad política radical. Hacia fines de 1969 se unió a la rama juvenil de la Unión de Centros Cooperativistas de UCAL mientras participaba también de un grupo que se reunía en la Parroquia San José, en Roque Sáenz Peña. Formó parte del lanzamiento de las Ligas chaqueñas en noviembre de 1970 y rápidamente se transformó en uno de los máximos dirigentes de la organización. Fue asesinado por miembros de la policía provincial el 21 de abril de 1979 a los 28 años en la zona de Colonia La Matanza. Al respecto véase Registro Único de la Verdad de la Comisión Provincial de la Memoria de Chaco, disponible en http://comisionporlamemoria.chaco.gov.ar/ruv_mapas/ web/

${ }^{48}$ Luís Piccoli, testimonio vertido el 12/05 en el Juicio Contraofensiva, Tribunal Federal de San Martín, Buenos Aires.
} 
ser que los liguistas «necesitábamos alimentarnos de sangre de los niños». 49

La represión desatada en el campo también se caracterizó por el asesinato de militantes campesinos. En el marco de los Operativos Toba ${ }^{50}$ se implementaron emboscadas y fusilamientos, presentados públicamente como enfrentamientos ${ }^{51}$ según los sumarios policiales de la dictadura. ${ }^{52}$ Ello ocurrió, por ejemplo, con los asesinatos de Carlos Piccoli y de Naró Gómez Estigarribia cuyas muertes han sido investigadas recientemente por la Secretaría de DDHH de la provincia con la colaboración del Equipo Argentino de Antropología Forense y cuyas historias retratan las características que asumió la represión a nivel local. ${ }^{53}$

\footnotetext{
${ }^{49}$ Vénica permaneció refugiado en el monte cuando se agudizó la persecución, donde vivió 4 años hasta que pudo exiliarse junto a su compañera IrminaKleimer. Ambos se ocuparon de alfabetizar a los hacheros rurales de Chaco.Testimonio de Remo Venica vertido el 11/06/ 2019 en el Juicio Contraofensiva, Tribunal Federal de San Martín, Buenos Aires.

${ }^{50}$ Vésase el informe «Operativo Toba. Subzona 23» del Equipo de Trabajo en los Archivos del Ejército, Dirección de Derechos Humanos y Derecho Internacional Humanitario, Ministerio de Defensa de la Nación (2014).

${ }^{51}$ En el noreste la práctica de encubrimiento de los crímenes de Estado comenzó a tomar estado público a partir de un caso emblemático, la Masacre de Margarita Belén. Gracias al testimonio, investigación y denuncia de los sobrevivientes, de los organismos de Derechos Humanos y de la Comisión de Derechos Humanos de la Cámara de Diputados de la provincia se logró desmentir la versión oficial que rápidamente difundió el gobierno militar (un enfrentamiento con «delincuentes subversivos»). En 2001 H.I.J.O.S. Chaco, la Asociación de ex Detenidos por Razones Políticas, familiares de las víctimas y el Centro de Estudios Legales y Sociales (CELS) reclamaron la reapertura de la causa, que fue elevada a juicio oral en febrero de 2009. El juicio comenzó en junio de 2010 y aproximadamente un año más tarde se condenó a prisión perpetua a los responsables. Al día de hoy se desconoce la identidad de varias de las víctimas de la Masacre. Sobre la masacre de Margarita Belén, véase Jorge Giles (2009) Alli va la vida, Tissembaum (1996) Desde Adentro y el film de Cecilia Fiel (2013) Margarita no es una flor.

${ }^{52}$ En 2010 el Juzgado Federal de Resistencia entregó a la Secretaría de DDHH de la provincia dos expedientes de la dictadura caratulados «Acuña Haydeé» $\mathrm{y}$ «Barrios», ambos por la ley $\mathrm{N}^{\circ} 20840$ sancionada en 1974 que penaba las actividades subversivas en todas sus modalidades. Los expedientes reunían todos los casos de supuesta lucha contra la subversión que venía llevando adelante la policía de la provincia. La aparición de estos documentos y el trabajo conjunto entre la Fiscalía provincial y el Equipo de Investigación de Antropología Forense posibilitó la judicialización del crimen de varios miembros de las Ligas Agrarias, luego de comprobarse que tras los supuestos enfrentamientos se habían fraguado fusilamientos y emboscadas. Al respecto, véase la entrevista realizada a Diego Vigay (2011), y la Sentencia condenatoria del Juicio Ligas Agrarias 1, dado a conocer el 25/06/2019.

${ }^{53}$ En 2015 tras las tareas de exhumación de sus restos, el EEAF confirmó que la muerte del ex dirigente agrario no había sido en un enfrentamiento. Durante el primer semestre de
} 
Escasos registros oficiales retratan la magnitud de los secuestros y asesinatos campesinos tras el golpe de Estado. ${ }^{54}$ Casi no existen datos de algunos liguistas de la Comisión Central que permanecen desaparecidos desde entonces, ${ }^{55}$ como Carlos Orianski, Taco Vallejos y Armando «Lagarto» Molina. Mario Piccoli, hermano de Carlos y emprendedor de la memorias de las Ligas estima que alrededor de 2000 personas de las Ligas fueron detenidas, entre dirigentes, familiares, amigos, vecinos, unas 200 fueron torturadas; y que de esas 200, 10 u 11 están desaparecidas o fueron asesinadas». Con el fin de «limpiar el nombre de Carlos, tildado de subversivo», comenzó a investigar este tema en los primeros años 90, reuniendo informalmente a las familias campesinas dispuestas a contar lo que sabían. De ese modo cuantificó las detenciones y desapariciones al interior del campesinado en Chaco. Sobre esas reuniones y testimonios no existen registros escritos ni audiovisuales.

2019 se realizó el primer juicio por violaciones de derechos humanos a miembros de las Ligas Agrarias. Pasaron ocho años desde que inició la investigación por crímenes de Estado en el campo chaqueño. En el medio, fallecieron muchos perpetradores y algunas víctimas también comienzan a tener problemas de salud como para movilizarse hasta Resistencia a prestar declaración. A fines de junio fueron condenados José Tadeo Bettolli y Alcides Sanferraiter por el homicidio de Piccoli y Estigarribia, a José Rodríguez Valiente por encubrimiento, y a 18 años a Eduardo Wischnivetzky por privación de libertad y tormentos a Modesto Mesa y los hermanos Hipólito y Santos Brites otros ex liguistas oriundos de Villa Berthet.

${ }^{54}$ A modo de excepción, véase el trabajo de recopilación de las historias de vida de los desaparecidos de las Ligas Agrarias realizado por el Registro Único de la Verdad, publicadas recientemente en el libro Historias de las Organizaciones Políticas en el Chaco y sus Militantes. Ligas Agrarias, UES y PRT/ERP, Vol 1, Colección RUV, Resistencia; Contexto Libros. 55 Véase, Mario Piccoli, testimonio vertido en el marco del Juicio «Ligas Agrarias «, 12/04/ 2019, Tribunal Oral $N^{\circ} 1$ de Resistencia, Chaco. También véase la entrevista realizada por la autora el 12/12/2019 en Sáenz Peña, Chaco.

${ }^{56}$ Esto guarda relación con la escueta relevancia que se ha otorgado al campo de estudios del campesinado como sujeto político en Argentina en el ámbito de las ciencias sociales. Los estudios rurales han minimizado la existencia de los sectores rurales subalternos como sujetos políticos, definiéndolos como «marginales» en la explicación de los fenómenos sociales. Véase, mi tesis de maestría «La configuración de las memorias y representaciones sociales sobre las Ligas Agrarias Chaqueñas desde la apertura democrática a la actualidad (19842011) [Tesis de Maestría]. Maestría en Investigación en Ciencias Sociales, Facultad de Ciencias Sociales, Universidad de Buenos Aires, marzo de 2015. 


\section{Conclusiones}

En el campo de Chaco la última dictadura profundizó un trabajo dehostigamiento y deslegitimación del activismo campesino iniciado años antes, con foco en la neutralización de las Ligas Agrarias. A partir de 1976 las fuerzas militares lograron el disciplinamiento de la sociedad rural, ya que, aprovechando el terreno preparado previamente por la policía provincial, cientos de miembros de las Ligas fueron detenidos y/ o desaparecidos, otros fusilados, bajo el argumento del enfrentamiento con la «subversión» y otros obligados al confinamiento en el monte.

Este trabajo constituyó un aporte a la construcción de conocimiento sobre la temporalidad de la represión al campesinado en el norte argentino durante la última dictadura. En particular, por un lado, detectó las continuidades que este fenómeno supuso respecto del periodo inmediatamente anterior: la represión en el campo no comenzó el 24 de marzo de 1976. La historia local desafía a los relatos asentados sobre fechas ligadas a democracias o dictaduras. El gobierno militar continuó con la propagación del ideario subversivo en torno a los dirigentes campesinos que ya venía siendo difundida por la prensa local desde hace varios años atrás (por parte de otros actores con importante influencia en la sociedad rural como el Obispo de Sáenz Peña Italo DI Stefano, quien oficializó la interrupción del apoyo eclesial a las Ligas en 1972). Para marzo de 1976 ya había arraigado en el campo la desconfianza intracomunitaria hacia los históricos referentes de las Ligas y esta creencia legitimaba su persecución.

Pero, por otro lado, este trabajo también echa luz sobre algunas rupturas respecto del ejercicio de la represión al campesinado a partir de 1976. La militarización permanente del campo es un aspecto que comenzó con el golpe. Su objetivo, la neutralización de la solidaridad de clase a través del secuestro y asesinato de sus cuadros medios, también. Si hasta entonces solo los máximos dirigentes eran vinculados con el comunismo de forma peyorativa, a partir de octubre de 1976, con la implementación de los Operativos Toba, todas las referencias locales del activismo, responsables del mantenimiento del contacto con los liguistas escondidos en el monte fueron perseguidos por su supuesto vínculo con el extremismo en el campo, padeciendo además la delación intracomunitaria.

Durante mucho tiempo el estigma y el tabú impidieron la enunciación en primera persona de la experiencia de las Ligas Agrarias. Este 
constituyó uno de los más productivos efectos de largo plazo de la represión a la población rural. Lentamente y de manera fragmentaria la historia reciente del campesinado en Chaco comenzó a emerger, tanto con el testimonio de ex liguistas y de otros activistas de la provincia que participaron de ese pasado, como a partir de la aparición de documentos y expedientes de la época. Poco a poco ello va repercutiendo en la celebración de juicios por crímenes de lesa humanidad a las Ligas, el primero de los cuales tuvo lugar en la primera mitad de 2019. Algunos de los testimonios examinados en este trabajo fueron vertidos en este y otros juicios. Salvo excepciones, como el caso de Lovey o de Venica, en esas audiencias los testigos evocaron por primera vez, luego de 40 años, la experiencia vivida y los acontecimientos traumáticos. En otros casos, los relatos fueron elaborados, por exclusiva solicitud de mi investigación, como el caso de Adelina de León, Jobino Fernández o Ramón Chávez, quienes nunca antes habían narrado públicamente su historia. Ello evidencia la falta de documentación de una porción no desdeñable tanto de la historia local chaqueña como de la historia rural en Argentina. Y da cuenta de los silencios que han circulado sobre las desapariciones de campesinos en nuestro país. ${ }^{56}$

\section{Referencias bibliográficas}

Archetti, E. (1988). Ideología y organización de las ligas agrarias del norte de Santa Fe 1971-1976. Desarrollo Económico, 28 (111), 447461.

Bartolomé, L. (1977). Populismo y diferenciación social agraria: las ligas agrarias en Misiones, Argentina. Cahiers du monde hispanique et luso-bresilien, (28), 141-165.

Bartolomé, L (1982). Base social e ideología en las movilizaciones agraristas en Misiones entre 1971 y 1975. Desarrollo Económico, 22 (85), 25-56.

Bidaseca, K. (2007) Colonos Insurgentes. Discursos heréticos y acción colectiva por el derecho a la tierra. Argentina 1900-2000. [Tesis Doctoral]. Facultad de Ciencias Sociales, Buenos Aires, Argentina: Universidad de Buenos Aires.

Borón, A. y Pegoraro, J. (1985). Las luchas sociales en el agro argentino. En González Casanova (comp.) Historia politica de los campesinos 
latinoamericanos, (pp. 149) Tomo 4. México, México: Siglo XXI/ IIS-UNAM.

Buzzella, N., Percíncula, A., Somma, L. (2008). Ligas Agrarias Correntinas: una aproximación a la mirada desde el actor. Encuentro Pre ALAS. Corrientes, Argentina.

Calvo C. (2015). La configuración de las memorias y representaciones sociales sobre las Ligas Agrarias Chaqueñas desde la apertura democrática a la actualidad (1984-2011), [Tesis de Maestría]. Maestría en Investigación en Ciencias Sociales, Facultad de Ciencias Sociales. Buenos Aires, Argentina: Universidad de Buenos Aires.

Calvo C. (2020). Las Ligas Agrarias de Chaco: procesos de movilización política y represión al campesinado Revista Conflicto Social, 13 (23), 160-194.

Calvo, C. y Percíncula, A. (2012). Ligas Agrarias en Chaco y Corrientes. Experiencias de organización campesina en contextos de transformación territorial. De Prácticas y Discursos. Cuadernos de Ciencias Sociales, 1 (1).

Carlino, A. (2007). El impacto de la globalización sobre el cultivo del algodón en el Chaco. Revista Indicadores Económicos, (46).

Colombo P. (2018). Construire (dans) les marges de 1'Etat, entre politiques de developpment» etc stratégies de contre-insurrection (Chaco, Argentina 1976-1980). Critique International, (79), 87-110.

Da Silva Catela, L. (2003). Apagón en el Ingenio, escrache en el museo. Tensiones y disputas entre memorias locales y memorias oficiales en torno a un episodio de represión de 1976. En P. Del Pino y E. Jelin (comps.). Luchas locales, commnidades e identidades. Madrid, España: Siglo XXI.

Da Silva Catela, L. (2006). El Estigma de la Memoria en Tumbaya. Revista Puentes, 61-66.

Da Silva Catela L. (2007). Poder Local y Violencia: Memorias de la represión en el Noroeste Argentino. En A. Isla (comp.). En los márgenes de la ley. Inseguridad y violencia en el cono sur. Buenos Aires, Argentina: Paidós.

Da Silva Catela L. y Esposito G. (2013). Indios, comunistas y guerrilleros: miedos y memorias de la lucha por tierras en la Quebrada de Humahuaca, Jujuy, Argentina. Revista CORPUS. Archivos virtuales de la Alteridad Americana, 3 (1). 
Ferragut J. (2015).De Productores Tabacaleros a productores liguistas: Las Ligas Agrarias correntinas y la formación de un sujeto colectivo (1972-1976). Jornadas de Investigadores de la Facultad de Humanidades y Ciencias Sociales. Posadas, Argentina: Universidad Nacional de Misiones.

Ferrara, F. (1973) ¿Qué son las Ligas Agrarias? Historia y Documentos de las organizaciones Campesinas del Nordeste Argentino. Buenos Aires, Argentina: Siglo XXI.

Figurelli, F. (2008). Rozando la memoria. Memoria y trabajo entre campesinos «sin tierra». AVA Revista de Antropología, (12), 27-41.

Franco, M. (2012).Un Enemigo para la Nación. Orden Interno, Violencia y «Subversión», 1973 - 1976. Buenos Aires: Fondo de Cultura Económica.

Galafassi G. (2005). Rebelión en el Campo. Las Ligas Agrarias de la Región Chaqueña y la Discusión del modelo dominante de Desarrollo Rural (1970-1976). Sujetos, Politicas y Representaciones del mundo rural. Argentina 1930-1976. Buenos Aires, Argentina: Siglo XXI.

Galafassi, G. (2007). Economía regional y emergencia de movimientos agrarios. La región Chaqueña de los años setenta. Revista NERA, $10(10), 11-36$.

Giles J. (2009). Allá va la vida. Buenos Aires: del Sol.

Isla A. y Taylor J. (1995). Terror e Identidad en los Andes. El caso del Noroeste Argentino. Revista Estudios y Debates, (2).

James, D. (2004) Doña Maria: Historia de vida, memoria e identidad politica. Buenos Aires, Argentina: Manantial.

Jelin E. y Del Pino P. (2003). Luchas Locales, comunidades e Identidades. Madrid, España: Siglo XXI.

Lasa C. (1985). Un proceso de mediación politica: Movimiento Rural y las Ligas Agrarias Chaqueñas [Tesis de grado], Facultad de Ciencias Sociales, UBA, Buenos Aires.

Lorenz F. (2007). Los Zapatos de Carlito. Buenos Aires: Norma.

Lovey, O. (2018). Las Ligas Agrarias. Una construcción Colectiva. Resistencia, Argentina: Contexto.

Maceira V. (2005). La recurrencia del recuerdo. Prácticas de historización entre trabajadores desocupados del conurbano bonaerense. Revista Prohistoria, politicas de la historia, IX (9), 153-178. 
Maneiro M. (2005).Como el Árbol Talado. Buenos Aires, Argentina: Al Margen.

Masin, D. (2009). Ligas Agrarias en la provincia de Santa Fe: una aproximación a la construcción y modos de acción de los actores sociales del norte y el sur de la provincia. V Jornadas de Jóvenes Investigadores, Instituto de Investigaciones Gino Germani, Facultad de Ciencias Sociales, Universidad de Buenos Aires. Buenos Aires, Argentina.

Miceli, J. (2006). Montemadre, Heroica historia de compromiso y dignidad. Reconquista, Argentina: edición propia.

Moyano, M. (1992). Organización popular y conciencia cristiana. En Autores Varios, 500 años de cristianismo en Argentina. Buenos Aires, Argentina: CEHILA.

Moyano M. (2020). El mundo rural en emergencia. Las Ligas Agrarias y las cooperativas y sindicatos rurales en el noreste argentino de los setenta. Buenos Aires, Argentina: Teseo.

Reyes Novaes, R. (2001). Lembrancas camponesas: repressao, sofrimento, perplexidade e medo. En N. Esterci, P. Fry e M. Goldenberg (Orgs.) Fazendo Antropologia no Brasil. Rio de Janeiro, Brasil: DP\&A.

Ribera Cucicanqui S. (1984).Oprimidos pero no Vencidos. Luchas del Campesinado Aymara y Quechua (1900-1980). La Paz, Bolivia: La Mirada Salvaje.

Rodríguez Maeso, S. (2011).Comunidades campesinas y la construcción de «la violencia» en el Perú: secretos, memorias y científicos sociales». En Autores Varios, La comunidad como pretexto: en torno al (re)surgimiento de las solidaridades comunitarias. Barcelona, España: Antrhropos.

Romero, L. (2007). Argentina: el tiempo largo de la violencia política. Introducción. En A. Perotin Dumon (dir.). Historizar el pasado vivo en América Latina. Recuperado de http://etica.uahurtado.cl/historizarelpasadovivo/es_contenido.php

Roze, J. (1992).Conflictos Agrarios en la Argentina 1 y 2. El Proceso Liguista. Buenos Aires, Argentina: CEAL.

Roze J. (2007).Lucha de Clases en el Chaco Contemporáneo. Resistencia, Argentina: Fundación Instituto de Estudios Sociales y Ambientales (Ideas). 
Roze, J. (2010).La larga marcha de un proceso social de conocimiento. Aprehendiendo el movimiento de las ligas agrarias del nordeste argentino. Resistencia, Argentina: Universidad Nacional de Misiones.

Salamanca C. (2015). Espacios, tiempos, identidades: políticas de la última dictadura militar en el Chaco Argentino. Revista de Estudios sobre Genocidio, 7 (10), 157-176. recuperado de https:// ri.conicet.gov.ar/handle/11336/70036

Vázquez C. (2015). Organización campesina. La Unión de Ligas Campesinas Formoseñas y la migración paraguaya (1960-1970). Revista Novapolis, (8), 13-29. Recuperado dehttp://novapolis.pyglobal. com/pdf/novapolis_ns_8.pdf

Vázquez C. (2017) La emergencia de la organización campesina en Formosa durante la década del sesenta, [Tesis de Maestría]. Maestría en Ciencias Sociales. Buenos Aires, Argentina: Universidad Nacional General Sarmiento.

Vezzetti, H. (2002).Pasado y presente. Guerra, dictadura y sociedad en la Argentina. Buenos Aires, Argentina: Siglo XXI.

Villalba, G. (2004) Las cooperativas como resistencia a la crisis del modelo sustitutivo entre los 60 y la actualidad, [Tesis de grado], Facultad de Humanidades de la Resistencia, Argentina: Universidad Nacional del Nordeste.

Theidon, K. (2004).Entre Prójimos. El Conflicto Armado Interno y la Politica de Reconciliación en Perú. Lima, Perú: Instituto de Estudios Peruanos.

Tissembaum, E. (1996). Desde Adentro. Resistencia, Argentina: Ediciones de Nuestra Cultura.

\section{Entrevistas}

Osvaldo Lovey, 17 de marzo de 2011. Tres Isletas, Chaco.

Ramón Chávez, 17 de marzo de 2011. Tres Isletas, Chaco

Jobino Fernández, 12 de julio de 2013, Tres Isletas, Chaco

Luís Rodríguez, 21 de febrero de 2018, Santa Fe.

Adelina de León, 5 de octubre de 2018 Buenos Aires.

Jorge Giles, 20 de septiembre de 2018, Buenos Aires.

Diego Vigay, 11 de abril de 2019, Resistencia. 
Juan Carlos Fernández, 30 de abril de 2019, Buenos Aires Mario Piccoli, 12 de diciembre de 2019 en Sáenz Peña

Testimonios vertidos en el «Juicio Ligas Agrarias l», en el Tribunal Federal No1, Resistencia, Chaco. 2019

Testimonios vertidos en el «Juicio Contraofensiva» Tribunal Federal No 4 de San Martín, Buenos Aires 2019. 